\title{
State of Charge Estimation for Off-Grid System Under Two Charge Controller Using Combination Methods
}

\author{
Waleed Karrar, Zhen Zhang* \\ College of Mechanical and Electrical Engineering, Hohai University, Changzhou, China \\ Email address: \\ zhen.zhang@hhu.edu.cn (Zhen Zhang), waleedkarrar1992@yahoo.com(W. Karrar) \\ *Corresponding author \\ To cite this article: \\ Waleed Karrar, Zhen Zhang. State of Charge Estimation for Off-Grid System Under Two Charge Controller Using Combination Methods. \\ International Journal of Systems Engineering. Vol. 2, No. 1, 2018, pp. 1-8. doi: 10.11648/j.ijse.20180201.11
}

Received: June 28, 2018; Accepted: July 9, 2018; Published: July 26, 2018

\begin{abstract}
The state of charge (SOC) estimation plays important role in the battery energy storage system (BESS). Nowadays many semiconductor companies are paying more and more attention and investment to support many researchers to implement the state of charge for the batteries storage. the key to optimize the batteries storage is determine SOC value based on accuracy methods. a number of brief methods for SOC determination have been studied and compared with traditional methods the adaptive methods shown precise result because didn't consider the dynamic effect of the batteries. In this paper, we use combination methods to estimate the SOC for lead-acid battery storage under two charge techniques namely Maximum Power Point Tracking - Plus Width Module (MPPT- PWM) when considering the effect of voltage drops on the estimation of SOC. The model uses the coulomb counting as an algorithm to determine the SOC and set it as a target in the backpropagation function in artificial neural network in MATLAB program (R2016a 64-bit (win64)). The simulation results show that the model is very precise to estimate the SOC in realistic operation.
\end{abstract}

Keywords: State of Charge (SOC), Lead-Acid Battery, Coulomb Counting (AH), Backpropagation (PB)

\section{Introduction}

Solar electric technology is growing very quickly and its worldwide use is increasing rapidly as well prices of other electric energy sources rise. Solar energy becomes very hot topic for researchers with significant rise of diesel price and subsequent environmental pollution concerns [1]. Solar energy systems have serval advantages that make them very desirable such as lower cost, environmental friendly (less emission of greenhouse gas (GHG) abundance source (obtained from sunlight).

Close to 1.3 billion people around the world do not have access to electricity and most of them live in rural areas in South Asia, Southeast Asia, and Sub-Saharan Africa [2]. There remains $18 \%$ of the world's population without access to electricity according to International Energy Agency [3]. The obvious way to reduce the cost and increase the availability of electricity is through economy scale provided by some forms of grid supply for a substantial proportion of the population. However, conventional grid connection is not a practical or economic solution [4]. Solar energy systems have two forms, namely, off-grid (island) and grid-connected. Both types of solar PV system are different in component and design. Both of the systems have backup but in the off-grid (stand-alone), the backup is required to connect with batteries to store the energy and use it during night or cloudy day. Meanwhile, the grid-connected connects directly with the grid. that can offer two options such as sell or buy from the utility.

The advantage of using the off-grid system can be suitable for several purposes in island, mountains and remote areas such as households. Small industries and institutions, Telecommunications and Health Centre vaccine refrigeration and lighting are typical examples.

Many studies have been carried out for the implementation of off-grid (stand-alone) PV electrification systems. The offgrid system has more economic benefits and high profits when compared with grid-connected. The efficacy is proved based on the effectiveness, levelized energy cost, net present worth (NPW), and annualized life-cycle cost [5-8] Besides, off-grid system becomes a promising option to be adopted for rural communities in order to improve electricity supply and economic development $[9,8,10]$. 
Using off-grid system in rural areas is more effective than using the combination system (hybrid system), that is related to the limited income in communities and high cost of diesel suppling $[11,12,13]$. The battery storage is preserved by using the controller to prevent the battery from overcharge and over discharge [14]. Besides that, the emission benefit of off-grid is optimally mitigated compared with a convenient resource for domestic household reported in rural Rwanda [15].

However, off grid system is more sensitive to factors such as shading, design on shorter day in the year, activities during the day and the future demand. These factors can increase the size of the component and directly influence the capital cost of the system as demonstrated $[16,17,18]$.

The rest of the paper is organized as follows: Section 2 presents review of state of charge (SOC) and implements the models while section 3 shows the design of the off-grid system. Section 4 shows the methodology and experiment setup, and Section 5 exemplifies the model of the state of the charge and simulation result and finally concludes and presents the future work. The results are obtained based on the combination methods namely coulomb counting $(\mathrm{AH})$ and artificial neural network backpropagation function (BP).

\section{Review on the State-of-the Art of SOC}

Various researches have been conducted to estimate the state of the charge (SOC) for the batteries during the charge and discharge and many of leading semiconductor companies are paying more and more attention to precise state of charge (SOC) indication.

Different methods have been established and available online to indicate the remaining energy inside the battery. This helps preventing the battery from overcharge and over discharge during required power supply. Precise models depend on complexity or simplicity of the model's parameter. For the first measurement to indicate the battery capacity has been established by Heyer in 1938. Heyer introduced a signal -meter on which the value of a storage battery capacity is indicated [19]. There are several available methods for SOC indication such as mathematical, electrical, electrochemical and adaptive methods.

A mathematical model uses different furcation and formulation to determine the accurate state of the charge for the lead acid batteries such as symbolic dynamic filtering (SDF), k-nearest-neighbor ( $\mathrm{kNN}$ ) regression algorithm. Other examples are probabilistic SOC estimation and considering probability distribution function of coefficients and third order model [20, 21, 22].

Electrical model is more accurate for data collection and depends on the electric measurement such as current, voltage and capacity. Despite this model's accuracy to predicate SOC, the model is very complex and sensitive for the environment operation. The model eventually exhibits difficulties in electrical engineering during implementation. For the drawbacks of this method, the error accrued during the measurement of data and the estimate of the initial state of charge are very difficult to obtain in real time for application [23, 24, 25].

Electrochemical models are very precise and complex in SOC estimation based on the internal resistance or on the specific gravity of electrolyte. The chemical interaction inside the battery is more affected by the temperature. When in high temperature, the material of electrolyte is very active in opposite when temperature is very low. The better prediction of SOC is observed when we consider the solid /electrolyte phase and the current. Others types of modeling are one-dimension model (ID) [26-27], pseudo -two dimensional (P2D) [28] model and single particle model [29, $30,31]$ which is more popular for predict the state of the charge prediction. Hence, the electrochemical model is very complex and complicated to improve that limits its application especially for electrical engineering and solving differential Equation is time consuming.

The main problem in designing an accurate SOC induction system is the unpredictability of both battery behavior and user behavior. Using the adaptive methods for SOC estimation is more accurate because internal parameters such as capacity and the resistance are not considered. Many of the adaptive models were already existing to indicate the state of charge for both offline and online. Those models are namely artificial neural network (ANN), extend Kalman filter (EKF), unscented Kalman filter (UKF), Neurofuzzy model, a support vector machine (SVM) [32-40], Those models are very accurate for SOC estimation as they depend on the training data collected during the experiment. For more accurate result between the actual state of charge and predict value should have a large data to simulate. The reason for this model high accuracy is that it does not take the physical or chemical behavior of the battery and is suitable for all types of battery.

A number of brief methods for SOC determination have been presented in the previous section. From the previous, we can note that the adaptive models are the best choice to predict SOC. Adaptive models input measured battery variables are current, voltage, impedance and temperature. The variables are used in order to accurately predict SOC and remaining time of use for application.

\section{System Configuration}

This paper concentrates on the optimum storage of the lead acid battery with the load 25W (LED) lighting for the system. The battery was supplied by two different technologies of charging namely MPPT and PWM. The battery storage optimization is accomplished by using data collection to calculate the efficiency of the charge and discharge related to SOC. This analysis helps us to estimate the lifetime of the battery and consider the effect of the method of charge (MPPT-PWM). This paper compares result of the real-time operation and simulation results to ensure the accuracy of the model by using MATLAB program. The important parameters to predict the SOC are the battery voltage, current discharge and remaining run time. 


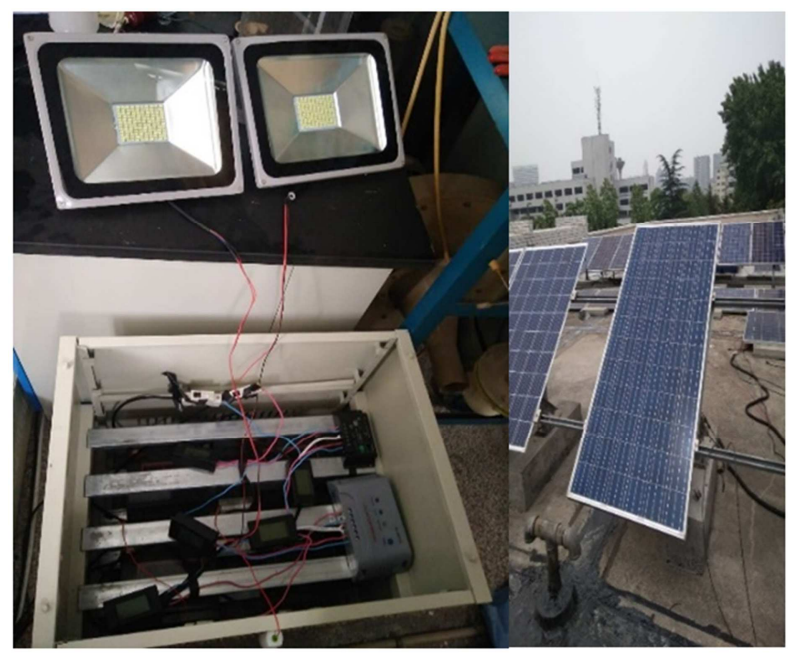

Figure 1. Off-grid component and PV module in roof of the Hohai lab.

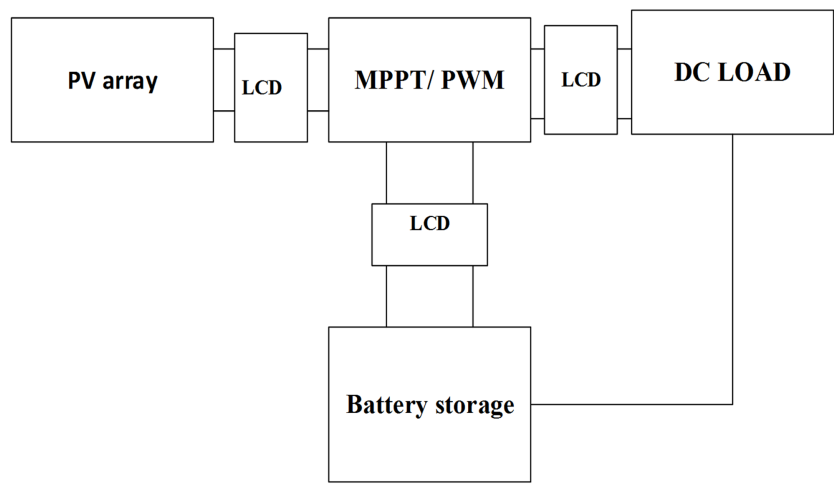

Figure 2. Block diagram of the off-grid system.

The amount of energy that a battery can store is called its capacity and measured in amp-hours. The battery can only deliver a fixed amount of energy and cannot supply more than the energy input. For the battery capacity of $40 \mathrm{AH}, 24$ volts for any system with two batteries (MMPT-PWM) are connected in series.

The experiment has been carried out in china Jiangsu Changzhou at the lab of Hohai University at the normal condition for the room temperature. The battery was charged and discharged for 20 steps each and the time is 5 minutes between each step. The battery was charged up to the 28.18 volts and the next day was discharged 24 volts.

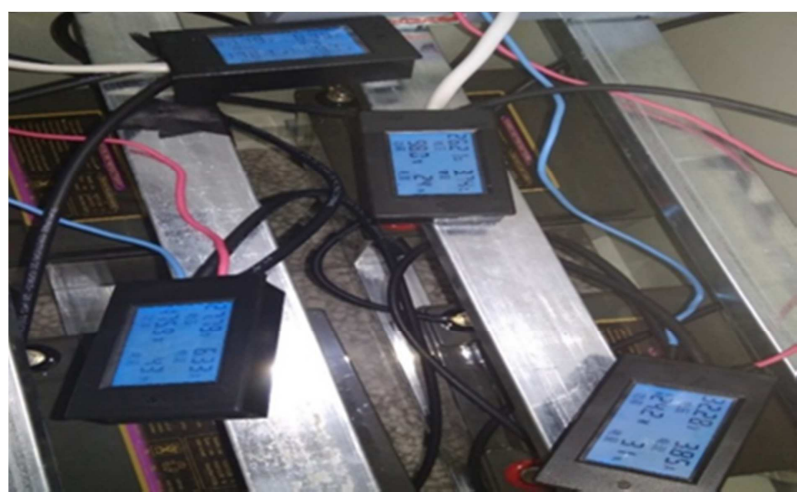

Figure 3. Data collection experiments setup.
In our experiment, the two-charge controller was used is PWM and MPPT. The controller capacity is (20-40A) and the MPPT presents high power and voltage compared with PWM. MPPTs mostly tend to be used in large systems, where getting the most out of the array results in significant cost gains for the system. Every system contains three liquidcrystal display (LCD) indictor to monitor power, voltage, current, and energy. The first LCD indicator monitors power supply between the PV array and charge to indicate the power. The second monitors the current charge and discharge between controller and battery while the third LCD indicates the power extracted from the battery between the charge and the load.

\subsection{PV Output Modeling}

$$
P V p v=\beta * P V \text { rate } *\left(\frac{\theta}{\theta_{0}}\right) *\left(1-\mathrm{Tc}_{0}(\mathrm{TA}-25) * \eta\right. \text { ref }
$$

where $P V p v=p v$ is the array rated power (W) and $\theta$ denotes the global insolation on $\mathrm{pv}$ array $\left(\mathrm{W} / \mathrm{m}^{2}\right) . \theta_{0}$ is the standard amount of insolation rating the capacity of $\mathrm{PV}\left(\mathrm{W} / \mathrm{m}^{2}\right)$, and $\mathrm{TA}$ is ambient temperature while $\mathrm{Tc}_{0}$ denotes temperature coefficient of the maximum power of $\mathrm{PV}$, and $\eta$ ref, the relative efficiency of PV modules.

For this experiment, the work is done using the PV modules with the power rating of $300 \mathrm{~W}$ from Trina solar manufacturing TSM-300PC14A. the specific characteristics of the modules are demonstrated below

Table 1. TSM-300PC14A-300W Specifications.

\begin{tabular}{ll}
\hline Maximum power (Pmax) & $\mathbf{3 0 0 \mathrm { W } + 3 \%}$ \\
\hline Maximum power voltage (Vmp) & $36.2 \mathrm{~V}$ \\
Maximum power current (Imp) & $8.30 \mathrm{~A}$ \\
Open circuit current (Isc) & $8.70 \mathrm{~A}$ \\
Open circuit voltage (Voc) & $45.0 \mathrm{~V}$ \\
Maximum system voltage & $\mathrm{DC} 1000 \mathrm{~V}$ \\
Maximum series fuse & $15 \mathrm{~A}$ \\
Module application & Class A \\
\hline
\end{tabular}

For field connections, the minimum $4 \mathrm{~mm}^{2}$ copper wires insulated for a minimum 90 degrees Celsius and electrical rating at STC $\left(\mathrm{AM}=1.5\right.$, Irradiance $\left.=1000 \mathrm{~W} / \mathrm{m}^{2}, \mathrm{Temp}=25^{\circ} \mathrm{C}\right)$.

\subsection{Battery Modeling}

The energy issue is the big challenge for some countries and how to store the energy after harvesting. The solution provision to the demand is of paramount importance for continuous supply without shortage (system stability). This can be achieved by using batteries energy storage system (BESS).

One of the most significant component of the solar power system especially the stand-alone system (off-grid system) was used to store the electric energy generated from chemical interaction inside. The electric energy was harvested from the sunlight by using the solar modules and this storage was used during the night. Battery backup represents the heart of the system and this research focuses on the charging and discharging battery under load lighting emitting diode (LED) with capacity of $25 \mathrm{~W}$. According to MPPT and PWM, the 
batteries have different purpose and performance characteristics. The lead acid is a type of popular batteries due to their cost and easier maintenance.

\subsection{The Model Implementation}

From the previous review based on the different methods, the coulomb counting presents the simple methods to implement depending on current of the charge and discharge within a period of time. When the battery is charging the current is negative while positive during discharge. This paper considers calculating the SOC in two cases. Firstly, without considering effect of voltage drop on estimate the SOC and secondly, considering the voltage drop. The backpropagation function in the artificial neural network to investigate the accuracy of the model is as well used. For $100 \%$ indicating battery full charge and $0 \%$ for empty battery, SOC can be calculated as

$$
S O C=100\left(1-\frac{1}{Q \max } \int_{t^{0}}^{t} \eta d, c * I(t) d t\right.
$$

where Qmax denotes the capacity of the battery (AH) and $\eta d$ is the discharge efficiency. $\eta c$ denotes charge efficiency and $I(t)$ is the charge or discharge current of battery (A). The energy feed to battery during charge can be expressed as

$$
Q e, c=\frac{\eta c * \Delta t * P c h, t}{Q \max }
$$

where $\eta c$ is charge efficiency and $\Delta t$ is the period of time for charging (minute). Pch, $t$ denotes the power of charge in a period of time (Wh) and Qmax is the capacity of the battery (AH).

The extract energy from battery during the discharge is as well expressed as

$$
Q e, d=\frac{\Delta t * P d, t}{Q m a x * \eta d}
$$

where $\eta d$ denotes charge efficiency, $\Delta \mathrm{t}$, the period of time for discharging (minute) and $P d, t$ is the power of discharge in period time (Wh). Qmax is the capacity of the battery (AH).

The optimized battery strategy for the energy inside the battery can be calculated by

$$
\text { PBESS }=\text { Pch }(\mathrm{t})-\mathrm{Pdis}(\mathrm{t})
$$

where $P$ dis $(t)$ denotes the power of discharge, and $P c h(t)$ is the power of charge.

\section{CASE 1}

Charge model

$$
\operatorname{SOC}(t)=\operatorname{SOC}(t-1)+\frac{\eta c * \Delta t * P c h, t}{Q \max }
$$

Discharge model

$$
\operatorname{SOC}(t)=\operatorname{SOC}(t-1)-\frac{\Delta t * P d, t}{Q \max * \eta d}
$$

CASE 2

Charge model

$$
\operatorname{SOC}(t)=\operatorname{SOC}(t-1)+\frac{\eta c * \Delta t * P c h, t}{Q \max }-\mathrm{Pv}
$$

Discharge model

$$
\operatorname{SOC}(t)=\operatorname{SOC}(t-1)-\frac{\Delta t * P d, t}{Q \max * \eta d}-\mathrm{Pv}
$$

where $\mathrm{Pv}$ is the voltage drops $(\mathrm{V})$

Figure 4. shows that the voltage drops can influence the SOC and also depending on the load capacity. As in this paper considers a very small load $(25 \mathrm{~W})$, the degradation on SOC becomes very slow during the time.

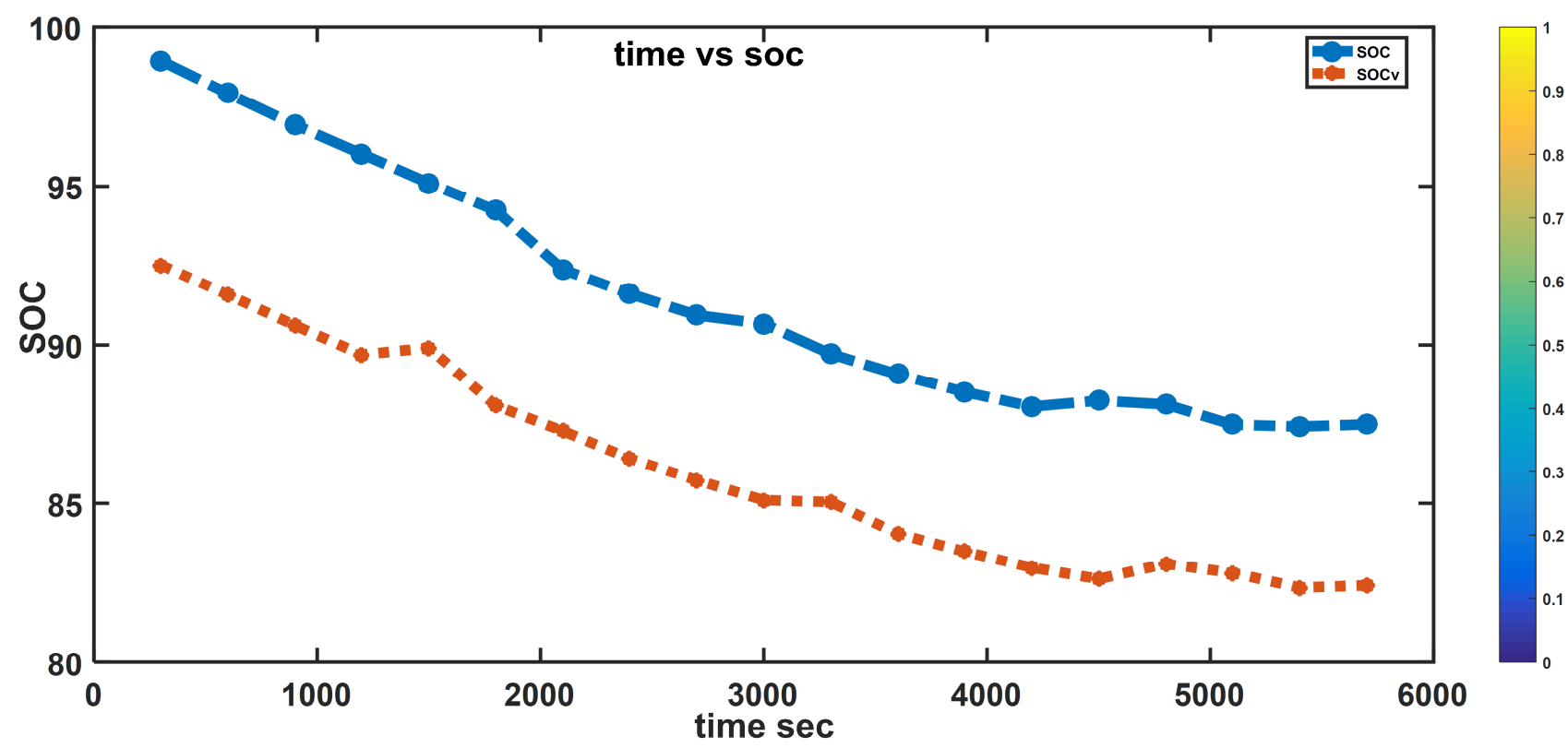

Figure 4. Exemplification of voltage drops influence. 
Constraints of the model

$$
\begin{gathered}
p_{d i s}^{m_{i} n} \leq p_{d i s} \leq p_{d i S}^{\max } \\
p_{c h}^{m_{i} n} \leq P_{C h} \leq p_{c h}^{\max } \\
S O C^{m_{i} n} \leq S O C \leq S O C^{\max }
\end{gathered}
$$

\section{Simulation and Results}

In this section, SOC is calculated based on the coulomb counting in previous models, i.e, equations (5) to (8), and the calculated SOC is used as a target in ANN. ANNs require massive data for training before they show the actual performance. In fact, using ANN to estimate complex problems based on their advantages in battery management system (BMS), can help obtaining very accurate performance if they were trained well without relying on thermal, chemical and physical model.

ANN consisting of inputs and outputs are made of neurons interconnected with each other. The weight in adaptive ANN continuously changes along the training data until reaching the targeted SOC value.
Show below is the block diagram of an adaptive ANN. The common technique used in this paper is the backpropagation or back- propagation of error which uses a steepest descent technique with repeat to the network parameter. To evaluate the performance of ANNs, we use the NARX which is a non-linear autoregressive with exogenous input (battery current, battery voltage, power charge and power discharge) based on the levenberg-marguardt backpropagation algorithm for training data and the number of hidden neurons is applied to be 10 , number of delays is (d) 2 . We predicate the value when the current value $(\mathrm{t})$ and past value $(\mathrm{t}-\mathrm{d})$ of an input series as well called external or exogenous series (output) are given. The output equation of this network is given

$$
y(t)=f(x(t-1) \ldots, x(t-d), y(t-1) \ldots, y(t-d) \ldots
$$

$f$ (.) represents an unknow function, $x(t)$ indicates the input time series consists of battery current, voltage, power charge and power discharge. $y(t)$ is the output time series which is the actual SOC determined from $\mathrm{AH}$, and $d$ denotes a delay parameter $(\mathrm{d}=1,2 \ldots$ etc. $)$

The block diagram of the methods is shown in Figure 5.

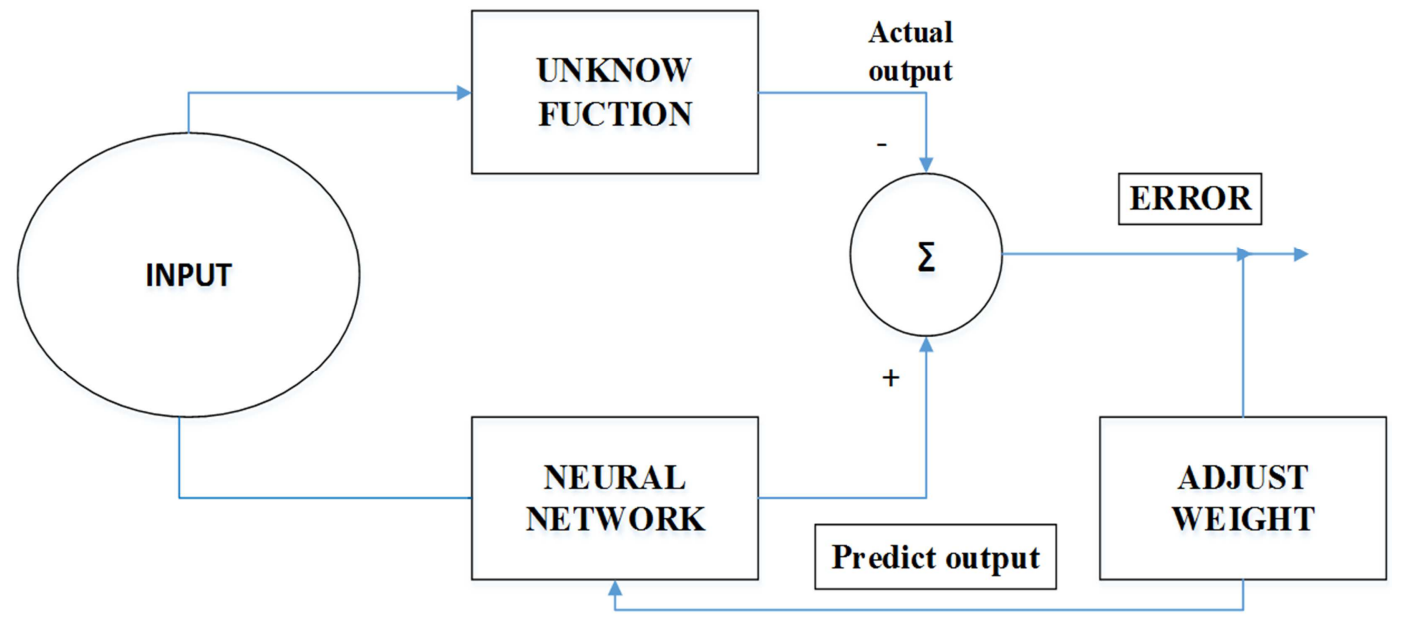

Figure 5. Operation of an Adaptive ANNs.

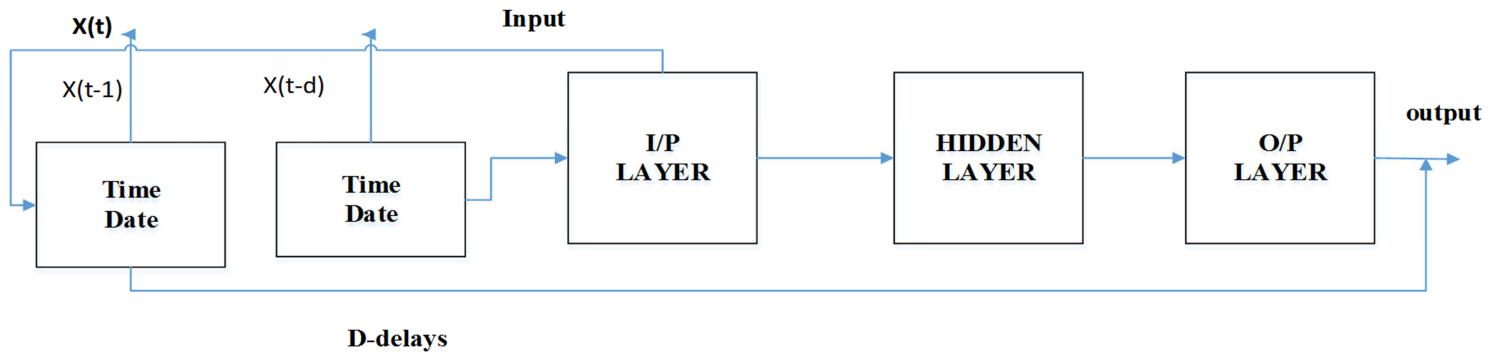

Figure 6. Block diagram of NARX feedback network.

The experiment assumes that self-discharge is constant for the lead acid battery and the temperature is assumed for the normal room conditions $\left(25^{\circ} \mathrm{C}\right)$. Firstly, by applying previous models with two cases when considering the voltage drops the results demonstrate that the voltage drop has an influence on the value of SOC as shown in Figure 4. Secondly, we test the model by using ANN back prorogation function voltage, current, power of charge and power of discharge as input and set the predicate value of the (SOC) as a target. A training algorithm is levenberg-marguardt to training data using the result to ensure the precision of the model as shown in Figure 9. From the simulation result, the mean square error and regression $\mathrm{R}$ Values are exemplified very accurate to mean that the model is more realistic to estimate the SOC. 

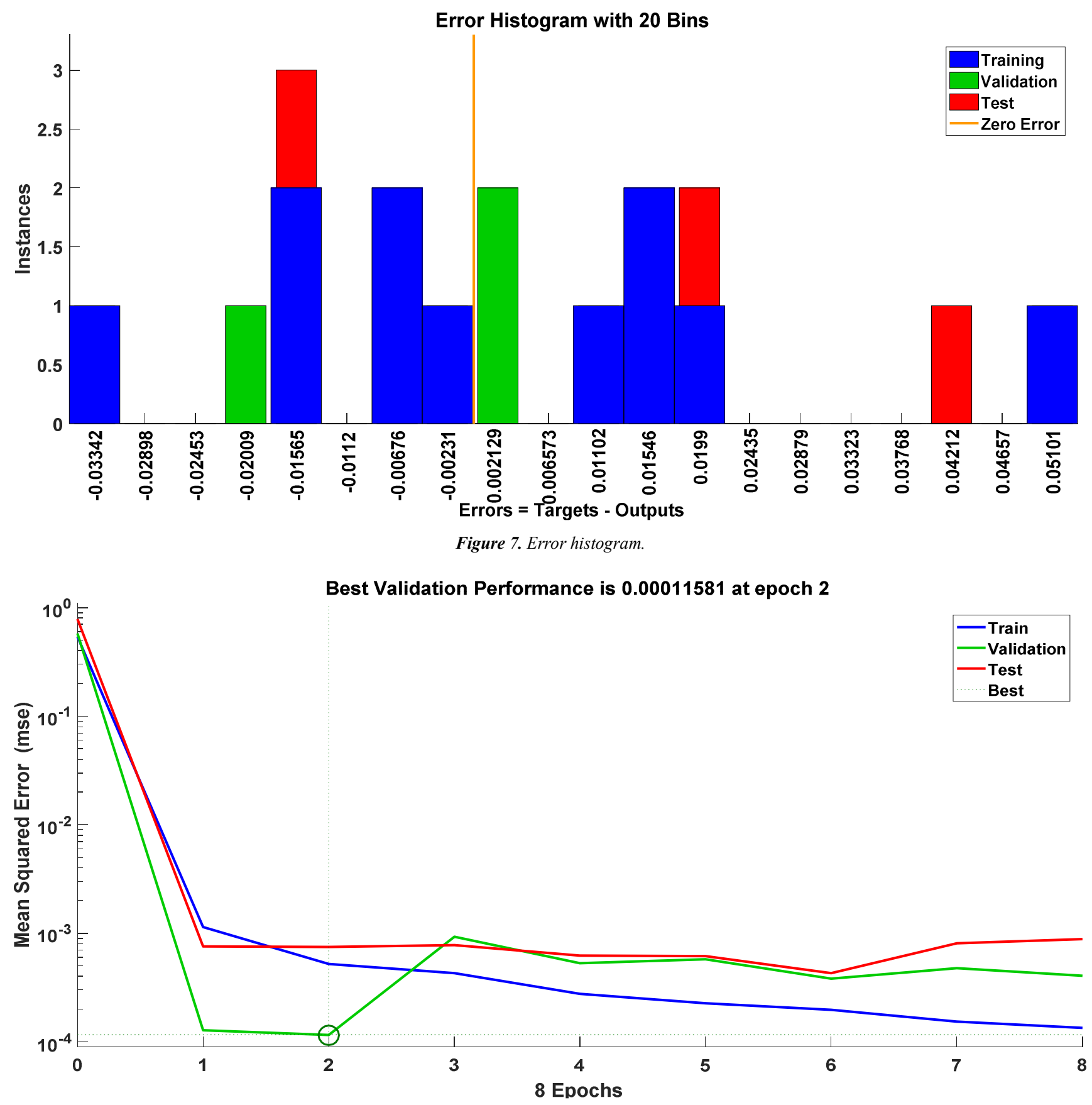

Figure 8. Show training performance.
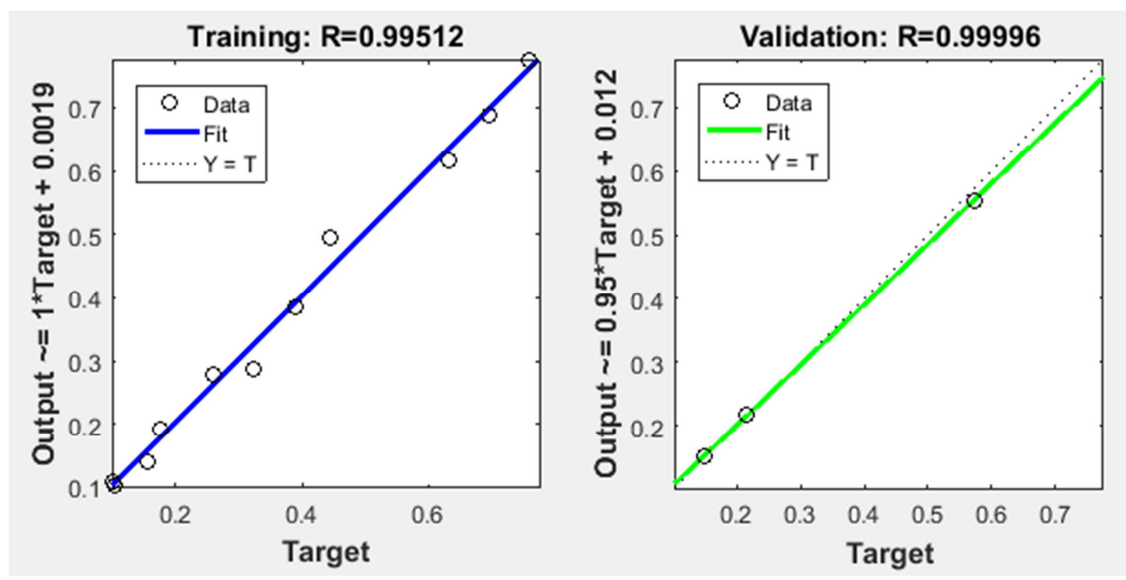

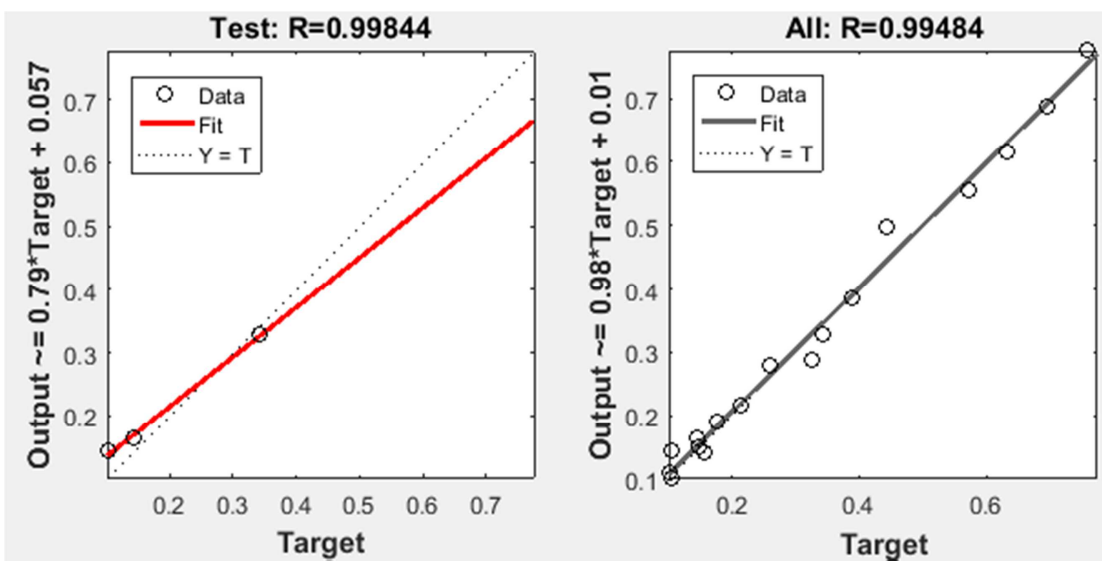

Figure 9. Show the plot regression.

\section{Conclusion}

This paper presents the estimate of state of the charge (SOC) for lead -acid battery storage under two charge technique (MPPT- PWM) using the coulomb counting (AH) to determine the SOC. The SOC is determined by taking into account two cases of estimation with and without considering the voltage drops. The results demonstrate that the voltage drops affect the value of SOC. Applying the estimate SOC by coulomb counting as a target in artificial neural network (ANNs) ensures accuracy of the model. Simulation results show that the model is very precise to estimate the SOC in realistic operation. For the future work, we recommend considering the self-discharge and temperature effect on SOC estimation.

\section{Acknowledgements}

This work was supported by the China Natural Science Foundation of Jiangsu Province (BK20151173), Key research project of Jiangsu province (Industry foresight and common key technologies BE2017063) ; National Natural Science Foundation of China ( 51777059 ) . The Fundamental Research Funds for the Central Universities (2018B22714).

\section{References}

[1] MA Elhadidy, SM Shaahid. Parametric study of hybrid (wind+ solar+ diesel) power generating systems. Renewable energy, 21 (2), pp.129-139. 2000.

[2] J Klugman. Sustainability and equity: A better future for all, Human development report 2011.

[3] K Malik, sustaining human progress Reducing vulnerabilities and building resilience. Human development report 2014, United Nations Development Programme, New York; 2014.

[4] S Szabo, K Bódis, T Huld, M Moner-Girona. Energy solutions in rural Africa, mapping electrification costs of distributed solar and diesel generation versus grid extension. Environmental Research Letters, 6 (3), p.034002. 2011.

[5] CA Vigneshwari, SS Velan, M Venkateshwaran, MA Mydeen, V Kirubakaran. Performance and Economic Study of on-grid and off-grid Solar Photovoltaic System, In Energy Efficient Technologies for Sustainability (ICEETS), International Conference on 2016, pp 239-244, 2016.

[6] DP Kaundinya, P Balachandra, NH Ravindranath, Gridconnected versus stand-alone energy systems for decentralized power-A review of literature. Renewable and Sustainable Energy Reviews, 13 (8), pp.2041-2050., 2009.

[7] A Roy, MA Kabir, Relative life cycle economic analysis of stand-alone solar PV and fossil fuel powered systems in Bangladesh with regard to load demand and market controlling factors. Renewable and Sustainable Energy Reviews. 16 (7), pp.4629-4637, 2012.

[8] U Akpan, M Essien, S Isihak, The impact of rural electrification on rural micro-enterprises in Niger Delta, Nigeria. Energy for Sustainable Development, 17 (5), pp.504509, 2013.

[9] KR Ajao, HA Ajimotokan, OT Popoola, HF Akande, Electric energy supply in Nigeria, decentralized energy approach, Cogeneration and Distributed Generation Journal, 24 (4), pp.34-50, 2009.

[10] SC Bhattacharyya. Electrification experiences from subSaharan Africa In Rural electrification through decentralised off-grid systems in developing countries, pp. 131-156, 2013.

[11] MM Mahmoud, IH Ibrik, Techno-economic feasibility of energy supply of remote villages in Palestine by PV-systems, diesel generators and electric grid, Renewable and Sustainable Energy Reviews, 10 (2), pp.128-138, 2006.

[12] A Ghafoor, A Munir, Design and economics analysis of an off-grid PV system for household electrification. Renewable and Sustainable Energy Reviews, 42, pp.496-502, 2015.

[13] C Jian, C Yanbo, Z Lihua, Design and research of off-grid wind-solar hybrid power generation systems. In Power Electronics Systems and Applications (PESA), 2011 4th International Conference on pp. 1-5.

[14] W Dengsheng, W Lidi, W Xiuhua, M Xiaofang, W Jun, G Dan, W Hui, Research and design of off-grid solar PV power generation LED display system. InControl and Decision Conference (CCDC), 2016 Chinese, pp. 333-337.

[15] CJ, Emmott AA Jaoude, A Urbina, NJ Ekins-Dawkes, J Nelson, Life cycle analysis of an off-grid solar charging kiosk, In Sustainable Energy Technologies (ICSET), 2012 IEEE Third International Conference on, pp. 12-17. 
[16] M Bouzguenda, A Al Omair, A Al Naeem, M Al-Muthaffar, OB Wazir, Design of an off-grid $2 \mathrm{~kW}$ solar PV system, In Ecological Vehicles and Renewable Energies (EVER), 2014 Ninth International Conference on, pp. 1-6.

[17] M Khatami, H Mortazavi, MR Mashhadi, M Oloomi, Designing an off-grid PV system, For a residential consumer in Mashhad-Iran. In AFRICON, 2013 pp, 1-5.

[18] N Narayan, J Popovic, JC Diehl, S Silvester, P Bauer, M Zeman, developing for developing nations, Exploring an affordable solar home system design, In Global Humanitarian Technology Conference (GHTC), 2016 pp. 474-480.

[19] B F W H Heyer, One-meter Battery Tester, US Patent 2, 225, 051, filedMay16 (1938).

[20] Y Li, Z Shen, A Ray, CD Rahn, Real-time estimation of leadacid battery parameters, A dynamic data-driven approach. Journal of Power Sources, 268, pp.758-764, 2014.

[21] JM Lujano-Rojas, GJ Osório, TD Mendes, JP Catalao, Stochastic modeling of lead-acid battery parameters. In Power Engineering Conference (UPEC), 2016 51st International Universities pp, 1-5.

[22] N Moubayed, J Kouta, A El-Ali, H Dernayka, R Outbib, Parameter identification of the lead-acid battery model. In Photovoltaic Specialists Conference, 2008. PVSC'08. 33rd IEEE 2008, pp. 1-6.

[23] KS Ng, CS Moo, YP Chen, YC Hsieh, Enhanced coulomb counting method for estimating state-of-charge and state-ofhealth of lithium-ion batteries. Applied energy. 86 (9), pp.1506-1511, 2009.

[24] O Caumont, P Le Moigne, C Rombaut, X Muneret, P Lenain, Energy gauge for lead-acid batteries in electric vehicles, IEEE Transactions on Energy Conversion, 15 (3), pp.354-360.2000.

[25] SK Rahimian, S Rayman, RE White, State of charge and loss of active material estimation of a lithium ion cell under low earth orbit condition using Kalman filtering approaches, Journal of the Electrochemical Society 159 (6), pp. A860A872.2012.

[26] KA Smith, CD Rahn, CY Wang, Control oriented 1D electrochemical model of lithium ion battery, Energy Conversion and management. 48 (9), pp.2565-2578, 2007.

[27] X Han, M Ouyang, L Lu, J Li, Simplification of physics-based electrochemical model for lithium ion battery on electric vehicle. Part II, Pseudo-two-dimensional model simplification and state of charge estimation. Journal of Power Sources. 278, pp.814-825, 2015.

[28] AP Schmidt, M Bitzer, ÁW Imre, L Guzzella, Experimentdriven electrochemical modeling and systematic parameterization for a lithium-ion battery cell. Journal of Power Sources. 2010 Aug 1; 195 (15):5071-80.
[29] H Fang, Y Wang, Z Sahinoglu, T Wada, S Hara, Adaptive estimation of state of charge for lithium-ion batteries. In American Control Conference (ACC), pp. 3485-3491. 2013.

[30] D Di Domenico, A Stefanopoulou, G Fiengo, Lithium-ion battery state of charge and critical surface charge estimation using an electrochemical model-based extended Kalman filter. Journal of dynamic systems, measurement, and control, 132 (6), p.061302, 2010.

[31] I Anand, BL Mathur, State of charge estimation of lead acid batteries using neural networks. In Circuits, Power and Computing Technologies (ICCPCT), 2013 International Conference on pp. 596-599, 2013.

[32] G Tina, G Capizzi, Improved lead-acid battery modelling for photovoltaic application by Recurrent Neural Networks. In Power Electronics, Electrical Drives, Automation and Motion, 2008. SPEEDAM 2008. International Symposium on pp. 1170-1174, 2008.

[33] K Yang, G Ouyang, P Zhang, Research upon the highcapacity lead-acid battery charge model. In Mechatronics and Automation, 2009. ICMA 2009. International Conference on pp. 5079-5083, 2009.

[34] GL Plett, Extended Kalman filtering for battery management systems of LiPB-based HEV battery packs: Part 3. State and parameter estimation. Journal of Power sources. 134 (2), pp.277-292, 2004.

[35] BS Bhangu, P Bentley, DA Stone, CM Bingham, State-ofcharge and state-of-health prediction of lead-acid batteries for hybrid electric vehicles using non-linear observers, In Power Electronics and Applications, 2005 European Conference on pp. 10-pp, 2005.

[36] W He, S Zhang, SS Ge, Adaptive control of a flexible crane system with the boundary output constraint. IEEE Trans. Industrial Electronics, Industrial Electronics, 61 (8), pp.41264133, 2014.

[37] MA Valdez, JA Valera, M Jojutla, OP Arteaga, Estimating SOC in lead-acid batteries using neural networks in a microcontroller-based charge-controller, In Neural Networks, 2006. IJCNN'06. International Joint Conference on pp. 27132719, 2006.

[38] N Khare, R Govil. Modeling automotive battery diagnostics, Power Electronics Technology, 34 (3), p.36, 2008.

[39] T Hansen, CJ Wang. Support vector-based battery state of charge estimator. Journal of Power Sources. 141 (2), pp.351$358,2005$.

[40] V Vapnik, The nature of statistical learning theory Springer New York Google Scholar 1995. 